\title{
Interrelationships between Writing Anxiety Dimensions and Writing Goal Orientation among Iraqi EFL Undergraduates
}

\author{
Ahmed Abdulateef Sabti \\ Department of English Language, Universiti Putra Malaysia, Malaysia, \\ ahmdartss@yahoo.com \\ Sabariah Md Rashid \\ Department of English Language, Universiti Putra Malaysia, Malaysia, \\ smrashid@upm.edu.my
}

\section{Ali Salman Hummadi}

University Technology Malaysia (UTM), Malaysia, alialanish1977@gmail.com

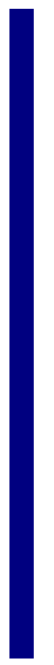

This study aimed to examine the relationships between facilitating writing anxiety (FWA), debilitating writing anxiety (DWA), mastery-approach goal (MAG), performance-approach goal (APPG) and performance-avoidance goal (AVOG). In total, 300 Iraqi undergraduate students participated in the study. A quantitative approach was applied in particular correlational design. Two questionnaires were utilized for data collection: The Second Language Writing Anxiety Inventory (SLWAI) and Achievement Goal Questionnaire (AGQ). The results of the study indicated that some students showed a high rate of debilitating anxiety, which led them to pursue performance-avoidance goal. Yet, the two factors of performanceavoidance goal and debilitating writing anxiety were negatively associated with the set of the three factors: mastery-approach goal, performance-approach goal and facilitating writing anxiety. Conversely, there were positive relationships between mastery-approach goal, performance-approach goal and facilitating writing anxiety. In the light of these findings, this study proposes that EFL learners need to consider the affective factors of debilitating anxiety and performance avoidance goal that are likely to undermine their confidence and motivation which may lead them to a maladaptive behavior.

Keywords: Iraqi undergraduate students, facilitating writing anxiety, debilitating writing anxiety, writing goal orientation

Citation: Sabti, A. A., Rashid, S., \& Hummadi, A. S. (2019). Interrelationships between Writing Anxiety Dimensions and Writing Goal Orientation among Iraqi EFL Undergraduates. International Journal of Instruction, 12(4), 529-544. https://doi.org/10.29333/iji.2019.12434a 


\section{INTRODUCTION}

Writing, which is deemed a demanding and intricate task for many EFL writers, necessitates a certain amount of "linguistics awareness, vocabulary, writing conventions and grammar". Lavelle et al. (2002) also described writing as "a complex cognitive activity involving attention at multiple levels: thematic, paragraph, sentence, grammatical and lexical" (p. 400). Besides that, writing skill acts for the most demanding skill since it can only be controlled across learning in comparison with the other three skills: speaking, reading and listening (Zailaini et al., 2015). Some academics contended that writing is not only seen as a cognitive activity, yet it is also perceived as an emotional activity (Pajares \& Valiante, 1997; Tsao et al., 2017). Consequently, it is highly connected with some affective variables, for instance, debilitating writing anxiety, facilitating writing anxiety and writing achievement motivation. These aforementioned affective variables are deemed contributing factors of learning and outcome (Cheng, 2004; Tsao et al., 2017).

Even if learners have an advanced level in writing, they may show a disappointing performance. This could be ascribed to some affective variables, dubbed writing anxiety (henceforth WA), and writing goal orientation (henceforth WGO) (Sabti, 2013; Schunk \& DiBenedetto, 2016; Senko, 2016). Some associated studies have also asserted that such factors affected EFL students' behavior that might steer to an unsatisfactory performance (Pajares \& Valiante, 2008; Erkan \& Saban, 2011). These affective factors such as lack of facilitating anxiety, motivation, and debilitating anxiety have been detected as negatively influencing EFL learners' writing performance in various studies (Chea \& Shumow, 2017; Cheng, 2004; Senko et al., 2011; Schunk \& Pajares, 2009; Tsao et al., 2017). However, some academics have mainly asserted that high values of facilitating anxiety and achievement motivation could enrich writing performance while high values of debilitating anxiety may influence writing performance adversely (Pajares \& Valiante, 2008; Sabti et al., 2016; Schunk \& DiBenedetto, 2016). These factors, therefore, act as contributing factors for successful language learning in EFL/ESL contexts (Erkan \& Saban, 2011; Tsao et al., 2017; Zhao, 2007).

According to Sabti (2013), most Iraqi students, who are as a part of EFL and Arab contexts, showed high level of anxiety. In the learning process, language anxiety is a complex psychological construct which is the major factor in the decline of students' academic achievement in the EFL/ESL contexts. As for writing goal orientation, it denotes a strong desire of individuals to complete their tasks they involved. Specifically, writing goal orientation may encompass either development of ability (i.e., mastery goals), demonstration of ability (i.e., performance-approach goals), or lacking the capacity to do something (i.e., performance-avoidance goals).

This study, therefore, seeks to examine the interrelationships among the two basic factors of writing anxiety: debilitating writing anxiety (henceforth DWA) and facilitating writing anxiety (henceforth FWA), and the three factors of writing goal orientation: mastery-approach goal (henceforth MAG), performance-approach goal (henceforth APPG) and performance-avoidance goal (henceforth AVOG). Four hypotheses were 
formulated to examine the interrelationships between aforementioned factors and presented as follows:

$H_{01}$ : There is no significant relationship between MAG, APPG and FWA.

$H_{02}$ : There is no significant relationship between AVOG and DWA.

$H_{03}$ : There is no significant relationship between AVOG, and the set of the three factors: MAG, APPG and FWA.

$H_{04}$ : There is no significant relationship between DWA, and the set of the three factors: MAG, APPG and FWA.

\section{Facilitating and Debilitating Writing Anxiety}

Facilitating anxiety is a positive factor that motivates a learner to engage in a new learning task, and emotionally leads to adopt approach behavior while debilitating anxiety motivates the learner to escape from the new learning task and emotionally leads to adopt avoidance behavior (Valmori, 2016). In other words, learners with high facilitating anxiety may attain a better grade than those with high debilitating anxiety and thus, facilitating anxiety can play a facilitating role in language learning. More accurately, facilitating anxiety acts as a facilitating effect or at least does not create an obstacle to learning because it increases and strengthens learners' motivation for learning. As for debilitating anxiety, it acts as an impairment of "the quality of performance by distracting attention and by dividing limited cognitive capacities in information processing while facilitating anxiety actually improves L2 performance by learners' enhanced efforts to accomplish a task" (Park \& French, 2013, p.468).

According to the Affective Filter Hypothesis theory of Krashen (1982), filter is up when students have high levels of debilitating anxiety that might prevent the delivery of input to the Language Acquisition Device (LAD) and may result in hindering individual's comprehension and achievement (negative Output). On the contrary, filter is down when students have high levels of facilitating anxiety that could facilitate the process of individual's comprehension and achievement (positive Output).

\section{Goal Orientation}

Goal orientation is defined as the reason behind students' achievement behavior (Chea \& Shumow, 2017). Goal orientation consists of three goals: mastery-approach goal, performance-approach goal and performance-avoidance goal. Mastery-approach goal orientation denotes a great deal of effort to gain understanding and competence in learning. In this light, learners are willing to deal with challenging tasks in order to learn and develop their competence.

Performance-approach goal orientation means a demonstration of competence or ability for the purpose of showing off. Learners who adopt performance-approach goal orientation tend to gain good grades for the purpose of outperforming their classmates. However, learners with performance-approach goal orientation tend to avoid challenging tasks compared with those who adopt mastery-approach goal orientation. In other words, performance-approach goal orientated learners have lower persistence in 
the face of difficulty (Chea \& Shumow, 2017; Dweck \& Leggett, 1988). Specifically, learners who espouse mastery- or performance-approach goal orientation are anticipated to study hard and gain similar achievement, but learners with a mastery-approach goal orientation may perform better than those with performance-approach goal orientation in demanding tasks and gaining long-term knowledge.

Performance-avoidance orientation, which is the third goal for goal orientation, refers to avoidance behavior of appearing incompetent in front of others (Chea \& Shumow, 2017; Elliot, 1999). Learners who espouse performance-avoidance goal orientation tend to avoid challenging tasks and easily abandon such tasks because they do not want to appear incompetent in front of others. This may be ascribed to a sense of loss of confidence and motivation. As such, unsatisfactory performance can be seen for such learners.

\section{METHOD}

\section{Research Design}

A quantitative approach was applied in particular correlational design which aims to assess relationships, consistency, and prediction (Ary, Jacob \& Sorensen, 2010). Precisely, a correlational study is applied to assess patterns of relationship among variables in one group of participants. In this study, the researcher seeks to examine the interrelationships between MAG, APPG, AVOG, FWA and DWA among 300 Iraqi freshman undergraduate students majoring in English language. These aforementioned factors are measured by two different questionnaires: Second Language Writing Anxiety Inventory (SLWAI) of Cheng (2004) and Achievement Goal Questionnaire (AGQ) Elliot and Church (1997).

\section{Participants}

The population of this study comprised 800 Iraqi freshman undergraduate students who were enrolled in the English language major programme at four colleges under the two universities from 2016 to 2017 (College of Education, College of Arts, College of Languages and College of Education for women) in two different universities in Iraq. These students were from one ethnic group and have the same mother tongue, i.e., Arabic language. Based on Krejcie and Morgan's (1970) techniques, 300 Iraqi freshman undergraduate students majoring in English language were selected.

\section{Instrumentation and Data Collection Procedures}

Data were collected via two different questionnaires: Second Language Writing Anxiety Inventory (SLWAI) and Achievement Goal Questionnaire (AGQ). The SLWAI was developed by Cheng (2004) which embraced 22 items in the shape of three factors, dubbed Somatic Anxiety, Avoidance Behavior anxiety and Cognitive Anxiety. Besides that, SLWAI was originally developed with debilitating effect only. To achieve the study objectives, SLWAI was modified to include both factors, namely facilitating anxiety and debilitating anxiety (See Appendix A). As for the second questionnaire (AGQ) developed by Elliot and Church (1997), it was adapted to elicit information pertaining to the students' achievement motivational goals towards writing skill (See Appendix B). 
These two questionnaires have been selected in this study because of their wellestablished reliability and validity in the literature. The questionnaires were rated using the five-level Likert scale from strongly agree (5) to strongly disagree (1). Data of this study were collected from the Iraqi EFL undergraduate students in the field of English major at Baghdad university in Iraq. The two questionnaires were translated into Arabic language in order to facilitate the understanding items of the questionnaires. After that, the questionnaires were back-translated from Arabic into English language to establish the construct validity.

\section{Data Analyses}

The data of the study was analyzed using inferential statistics. This information from the inferential statistics enabled the researcher to possess an overall view of the interrelationships among variables, dubbed MAG, APPG, AVOG, FWA and DWA. Additionally, for this inferential statistics analysis, Pearson Product-Moment Correlation Coefficient (PPMCC) was conducted on the respective data.

To determine a high, moderate or low relationship between two factors, the Rule of Thumb presented by Guildford (1973) was adopted for interpreting the relationship strength. Table 1 summarizes Guildford's (1973) Rule of Thumb for interpretation of correlation coefficient (r).

Table 1

Guildford's (1973) Rule of Thumb for Interpretation of correlation coefficient (r)

\begin{tabular}{ll}
\hline $\mathrm{r}$ & Interpretation \\
\hline$<0.2$ & Negligible positive/negative correlation \\
$0.2-0.4$ & Low positive/negative correlation \\
$0.4-0.7$ & Moderate positive/negative correlation \\
$0.7-0.9$ & High positive/negative correlation \\
$>0.9$ & Very high positive/negative correlation \\
\hline
\end{tabular}

\section{FINDINGS}

This section which aims to test the four hypotheses that were formulated for this study, presents the results of the interrelationships between MAG, APPG, AVOG, FWA and DWA. The results are presented to subsections according to each hypothesis. Prior to hypotheses testing, reliability and normality tests were carried out to assess the consistency and validity of the questionnaires as summarized in the next two tables (Table 2 \& Table 3).

Table 2

Internal Consistency Reliability of Writing Anxiety

\begin{tabular}{lll}
\hline Reliability Statistics & Cronbach's Alpha & No of Items \\
\hline Facilitating Writing Anxiety Factor & .817 & 10 \\
Debilitating Writing Anxiety Factor & .845 & 12 \\
Writing Anxiety Variable & .774 & 22 \\
\hline
\end{tabular}

The internal consistency reliability of the anxiety variable was made in three phases. The Cronbach's alpha was applied to assess the reliability for each factor of the 
questionnaire and for the complete questionnaire. The results reveal that the two factors showed a high internal consistency reliability as summarized in Table 2 wherein $(\alpha=$ $.817)$ is for facilitating writing anxiety factor, and $(\alpha=.845)$ for debilitating writing anxiety factor. The scores for the two factors indicated a high internal consistency reliability, yet on the other hand, the anxiety variable as the complete questionnaire showed an acceptable level of internal consistency reliability $(\alpha=.774)$.

Table 3

Internal Consistency Reliability of Writing Goal Orientation

\begin{tabular}{lll}
\hline Reliability Statistics & Cronbach's Alpha & No of Items \\
\hline Mastery-approach Goal Factor & .815 & 6 \\
Performance-approach Goal Factor & .929 & 6 \\
Performance-avoidance Goal Factor & .842 & 6 \\
Achievement Motivation Variable & .910 & 18 \\
\hline
\end{tabular}

The internal consistency reliability of the achievement motivation variable was made in four phases for each factor of the questionnaire and for the complete questionnaire. The results demonstrate that the achievement motivation variable also displayed high scores for internal consistency reliability on the three factors and the complete variable as illustrated in Table 3. The results exhibit that Mastery-approach goal factor $(\alpha=.815)$, Performance-approach goal factor $(\alpha=.929)$, Performance-avoidance goal factor $(\alpha=$ $.842)$ and the complete questionnaire $(\alpha=.910)$.

\section{Results of the First Hypothesis}

The section addresses the results of the first hypothesis which examines the relationships between MAG, APPG and FWA. For ease of reference, the first hypothesis is presented as follows:

$H_{01}$ : There is no significant relationship between MAG, APPG and FWA.

The results of the $H_{01}$ of the relationships between the aforementioned factors are tabulated in the next table (Table 4).

Table 4

Results of the Relationship Between the Factors of MAG, APPG and FWA

\begin{tabular}{|c|c|c|c|c|}
\hline \multicolumn{5}{|c|}{ Correlations } \\
\hline & & MAG & APPG & FWA \\
\hline \multirow{3}{*}{ MAG } & Pearson Correlation & 1 & .409 & .138 \\
\hline & Sig. (2-tailed) & & .000 & .017 \\
\hline & $\mathrm{N}$ & 300 & 300 & 300 \\
\hline \multirow{3}{*}{ APPG } & Pearson Correlation & .409 & 1 & .202 \\
\hline & Sig. (2-tailed) & .000 & & .000 \\
\hline & $\mathrm{N}$ & 300 & 300 & 300 \\
\hline \multirow{3}{*}{ FWA } & Pearson Correlation & .138 & .202 & 1 \\
\hline & Sig. (2-tailed) & .017 & .000 & \\
\hline & $\mathrm{N}$ & 300 & 300 & 300 \\
\hline
\end{tabular}

p-value $\leq 0.05$ 
Based on the results shown in Table 4, there were significant and positive relationships between MAG, APPG and FWA. A moderate and positive relationship between (e.g., MAG \& APPG: $r(298)=.409, p<0.05)$ was detected, whereas there were low and positive relationships between (e.g., MAG \& FWA: $r(298)=.138, p<0.05$; FWA \& APPG: $r(298)=202, p<0.05)$. This suggests that these factors act as powerful predictors of a learner's performance. Since the significant value is smaller than $\alpha$ at .05 level of significance, the null hypothesis $\left(H_{01}\right)$ was rejected. Therefore, there is a significant and positive relationship between MAG, APPG and FWA.

\section{Results of the Second Hypothesis}

This section provides an explanation on the second hypothesis that addresses the relationship between AVOG and DWA.

$H_{02}$ : There is no significant relationship between AVOG and DWA."'

Table 5 presents the results of the $H_{02}$ which examines the relationship between AVOG and DWA.

Table 5

Results of the Relationship Between AVOG and DWA

\begin{tabular}{|c|c|c|c|}
\hline \multicolumn{4}{|c|}{ Correlations } \\
\hline & & AVOG & DWA \\
\hline \multirow{3}{*}{ AVOG } & Pearson Correlation & 1 & .097 \\
\hline & Sig. (2-tailed) & & .043 \\
\hline & $\mathrm{N}$ & 300 & 300 \\
\hline \multirow{3}{*}{ DWA } & Pearson Correlation & .097 & 1 \\
\hline & Sig. (2-tailed) & .043 & \\
\hline & $\mathrm{N}$ & 300 & 300 \\
\hline
\end{tabular}

As seen by Table 5, the results show that these two factors: AVOG and DWA were positively associated but with a very negligible degree of relationship $r(298)=.097$. Apart from the strength of the relationship, these two factors were also significantly associated $(p=0.043)$. Based on this, the significant value (0.043) is smaller than $\alpha$ at ( $p$ $<0.05)$, and as the significant value is smaller than $\alpha$ at .05 level of significance, the null hypothesis $\left(H_{02}\right)$ was also rejected. Therefore, there is a significant and positive relationship between AVOG and DWA.

\section{Results of the Third Hypothesis}

This section provides the results of the third hypothesis.

$H_{03}$ : There is no significant relationship between AVOG, and the set of the three factors: MAG, APPG and FWA."

Table 6 provides the results of the $H_{03}$ which examines the relationship between AVOG, and the set of the three factors: MAG, APPG and FWA. 
Table 6

Results of the Relationship of AVOG with MAG, APPG and FWA

\begin{tabular}{|c|c|c|c|c|c|}
\hline \multicolumn{6}{|c|}{ Correlations } \\
\hline & & AVOG & MAG & APPG & FWA \\
\hline \multirow{3}{*}{ AVOG } & Pearson Correlation & 1 & -.221 & -.375 & -.171 \\
\hline & Sig. (2-tailed) & & .000 & .000 & .003 \\
\hline & $\mathrm{N}$ & 300 & 300 & 300 & 300 \\
\hline \multirow{3}{*}{ MAG } & Pearson Correlation & -.221 & 1 & .409 & .138 \\
\hline & Sig. (2-tailed) & .000 & & .000 & .017 \\
\hline & $\mathrm{N}$ & 300 & 300 & 300 & 300 \\
\hline \multirow{3}{*}{ APPG } & Pearson Correlation & -.375 & .409 & 1 & .202 \\
\hline & Sig. (2-tailed) & .000 & .000 & & .000 \\
\hline & $\mathrm{N}$ & 300 & 300 & 300 & 300 \\
\hline \multirow{3}{*}{ FWA } & Pearson Correlation & -.171 & .138 & .202 & 1 \\
\hline & Sig. (2-tailed) & .003 & .017 & .000 & \\
\hline & $\mathrm{N}$ & 300 & 300 & 300 & 300 \\
\hline
\end{tabular}

Based on Table 6, the results demonstrate that AVOG was significantly and negatively associated with the set of the three factors: MAG, APPG and FWA. With differences in the relationship strength, the relationship between AVOG and two other factors MAG and APPG recorded as low and negative (e.g., AVOG \& MAG: $r(298)=-.221, p<$ 0.05; AVOG \& APPG: $r(298)=-.375, p<0.05)$ while the relationship with FWA labelled as negligible and negative (e.g., AVOG \& FWA: $r(298)=-.171, p<0.05$ ). Since the significant value is smaller than $\alpha$ at .05 level of significance, the null hypothesis $\left(H_{03}\right)$ was also rejected. Therefore, there is a significant relationship between AVOG and the set of the three factors: MAG, APPG and FWA. In other words, the factor AVOG and the set of the three factors: MAG, APPG and FWA were negatively associated.

\section{Results of the Fourth Hypothesis}

This section focuses on the results of the fourth hypothesis.

$H_{04}$ : There is no significant relationship between DWA, and the set of the three factors: MAG, APPG and FWA."'”

Table 7 shows the results of the $H_{04}$ which examines the relationship between DWA, and the set of the three factors: MAG, APPG and FWA. 
Table 7

$\underline{\text { Results of the Relationship of DWA with MAG, APP.M and FWA }}$

\begin{tabular}{|c|c|c|c|c|c|}
\hline \multicolumn{6}{|c|}{ Correlations } \\
\hline & & DWA & MAG & APPG & FWA \\
\hline \multirow{3}{*}{ DWA } & Pearson Correlation & 1 & -.082 & -.117 & -.809 \\
\hline & Sig. (2-tailed) & & .154 & .043 & .000 \\
\hline & $\mathrm{N}$ & 300 & 300 & 300 & 300 \\
\hline \multirow{3}{*}{ MAG } & Pearson Correlation & -.082 & 1 & .409 & .138 \\
\hline & Sig. (2-tailed) & .154 & & .000 & .017 \\
\hline & $\mathrm{N}$ & 300 & 300 & 300 & 300 \\
\hline \multirow{3}{*}{ APPG } & & -.117 & .409 & 1 & .202 \\
\hline & & .043 & .000 & & .000 \\
\hline & & 300 & 300 & 300 & 300 \\
\hline \multirow{3}{*}{ FWA } & Pearson Correlation & -.809 & .138 & .202 & 1 \\
\hline & Sig. (2-tailed) & .000 & .017 & .000 & \\
\hline & $\mathrm{N}$ & 300 & 300 & 300 & 300 \\
\hline
\end{tabular}

As shown by Table 7, the results illustrate that DWA recorded a negligible and negative relationship with APPG (DWA \& APPG: $r(298)=-.117 ; p<0.05)$ while a high and negative relationship was observed between DWA and FWA (DWA \& FWA: $r(298)=-$ $.809, p<0.05)$. According to the significance level, $p$-value was smaller than the value of $\alpha$ at $(p<0.05)$ and hence, DWA was significantly associated with both factors: APPG and FWA. Nonetheless, DWA recorded a negligible and negative relationship with MAG, but the relationship was not significant (DWA \& MAG: $r(298)=-.082 ; p>$ 0.05). As the significant level values of the two relationships (e.g., DWA \& APPG; DWA \& FWA) were smaller than the value of $\alpha$ at $(\mathrm{p}<0.05)$ and one value of the relationship (e.g., DWA \& MAG, $p=0.154$ ) was greater than the value of $\alpha$ at $(\mathrm{p}<$ $0.05)$, the $H_{04}$ was partially rejected.

\section{DISCUSSION}

The findings of this study revealed that there were positive relationships between MAG, APPG and FWA. This indicates that learners with high values of these factors: MAG, APPG and FWA could strengthen their confidence and motivation which may lead them to perform better during tasks. More accurately, MAG, APPG and FWA may highly operate as powerful predictors of learners' performance. As such, such factors can bring into positive reinforcement to improve an individual's competence. In other words, high levels of these factors: MAG, APPG and FWA might drive learner to an adaptive behavior and could lead to success in some academic areas (Chea \& Shumow, 2017; Senko \& Miles, 2008). The findings of the present study are parallel to previous findings reporting that learners' achievement was positively associated with the factors: MAG, APPG and FWA (Csizér \& Piniel, 2013; Kader, 2016; Senko, 2016;). However, in face of difficulty, performance-approach oriented students may simply give up and thus, they may not succeed academically. This may be attributed to their short-term gain of knowledge wherein performance-approach oriented students largely focus on 
demonstrating their competence rather than developing it for the purpose of outperforming others (Chea \& Shumow, 2017; Dweck \& Leggett, 1988). In this case, this goal may potentially cause avoidance behaviors when faced with unforeseen obstacles such as when the tasks are confusing or not clearly defined.

The findings also showed a significant and positive relationship between DWA and AVOG. These findings confirm Senko's (2016) belief that "performance-avoidance goals do elicit high anxiety and threat appraisals, promote risk-avoidance, disrupt task focus, and undermine academic achievement." (p. 80). It can be inferred that individuals with high values of DWA and AVOG tend to avoid tasks compared to those who have low levels of these factors. Specifically, individuals with high degree in writing performance-avoidance goal orientation attempt to avoid demanding tasks in order not to appear incompetent in front of others because they feel unable to perform well in such tasks.

Added to this, high levels of DWA act as a debilitating effect on individuals' performance and may feel a sense of loss of confidence and motivation. The findings of this study are consistent with a study conducted by Huwari and Aziz (2011) which revealed that individuals with high rates of DWA perhaps exhibit some characteristics such as a lack of confidence and motivation. Individuals with such characteristics tend to write irregularly and may simply give up. These characteristics could lead to produce a paper of low quality (i.e., grammatical errors and lack of well-developed ideas). Hence, individuals with such characteristics need positive feedback (e.g., classmates or teachers, family members) as strong support to encourage them to develop their competence (Goodman \& Cirka, 2009; Tsao et al., 2017; Yan et al., 2018).

In this study, on the contrary, a negative relationship was perceived between the set of two factors: AVOG and DWA and the set of three factors: MAG, APPG and FWA. As the factors: DWA and AVOG were negatively associated with the three factors: MAG, APPG and FWA, this may be justified by the fact that these two factors may be detrimental to the self-confidence of individuals that may chiefly have a negative effect on their behavior, and thus, to a large extent, may drive to poor performance in the tasks they engaged in. The findings of this study lend support to findings of the past studies by contending that DWA and AVOG were negatively associated with the three factors: MAG, APPG and FWA (Maehr \& Zusho, 2009; Senko, 2016). In short, the factors: DWA and AVOG could mainly push learners to avoid engaging in a certain task as they feel they are incompetent and may largely bring them towards the zone of failure ending with poor performance. Thus, it is essential for teachers to make their students aware of the strong impact of DWA and AVOG which may hugely lead to the negative academic achievement. To reduce the impact of these influencing factors and to enhance students' motivation, teachers need to promote their competence by incorporating more writing activities into their classrooms.

\section{CONCLUSION, IMPLICATIONS AND RECOMMENDATIONS}

In the current study, a correlational design was applied to examine the interrelationships between the two factors of writing anxiety: FWA and DWA and the three factors of 
writing goal orientation: MAG, APPG and AVOG. This study demonstrated a significant and positive relationship between MAG, APPG and FWA. This study confirmed that these factors are effective in reducing students' stress, tension and debilitating anxiety. In other words, this reinforces the importance of these factors, which can powerfully strengthen learners' motivation in language learning and to raise self-awareness about debilitating anxiety and avoidance goal.

On the contrary, this study manifested that the set of two factors: DWA and AVOG play negative factors that could influence individuals' motivation and confidence based on findings obtained from a tertiary level of Iraqi EFL undergraduate students. According to these findings, these two factors (e.g., DWA \& AVOG) may highly act as weak predictors and an adverse impact on learners' achievement. Likewise, these two factors were adversely associated with some factors such as MAG, APPG and FWA.

In this light, it is imperative to establish a comfortable learning atmosphere to assist learners to reduce their DWA and AVOG. Also, it is part of teachers' job to instil confidence into their learners and may gradually assuage their fear of being appraised and might encourage them to develop their language competence. This can be fulfilled by avoiding or reducing the provision of negative feedback from teachers, classmates or family members on students' performance and providing the opportunities for learners to create positive perceptions about their ability. The gradual decrease of DWA and AVOG can greatly stimulate learners to enhance their language competence. The current study, therefore, suggests that teachers need to work on the factors: FWA, MAG and APPG which can play a substantial role in minimizing learners' DWA and AVOG levels.

The findings of the present study may highly serve as a strong base for future research to take further actions to examine the aforementioned factors in relation to EFL writing performance. Specifically, future research can examine the effects of the aforementioned factors on EFL writing performance. Moreover, future research can also include the factor gender which highly plays a significant role in influencing the results.

\section{REFERENCES}

Ary, D., Jacob, L. C., \& Sorensen, C. (2010). Introduction to research in education. Belmont, CA: Thomson Wadsworth.

Chea, S., \& Shumow, L. (2017). The relationships among writing self-efficacy, writing goal orientation, and writing achievement1. Language Education in Asia, 5(2), 253-269. http://dx.doi.org/10.5746/LEiA/14/V5/I2/A07/Chea_Shumow.

Cheng, Y. S. (2004). A measure of second language writing anxiety: Scale development and preliminary validation. Journal of second language writing, 13(4), 313-335.

Csizér, K., \& Piniel, K. (2013). Motivation, anxiety and self-efficacy: the interrelationship of individual variables in the secondary school context. Studies in Second Language Learning and Teaching, 3(4), 523-550. 
Dweck, C. S., \& Leggett, E. L. (1988). A social-cognitive approach to motivation and personality. Psychological review, 95(2), 256.

Elliot, A. J. (1999). Approach and avoidance motivation and achievement goals. Educational psychologist, 34(3), 169-189.

Elliot, A. J., \& Church, M. A. (1997). A hierarchical model of approach and avoidance achievement motivation. Journal of personality and social psychology, 72(1), 218-232.

Erkan, Y. D., \& Saban, A. I. (2011). Writing performance relative to writing apprehension, self-efficacy in, writing and attitudes towards writing: A Correlational Study in Turkish Tertiary-Level EFL. The Asian EFL Journal Quarterly, 13(1), 163191.

Goodman, S. B., \& Cirka, C. C. (2009). Efficacy and anxiety: An examination of writing attitudes in a first-year seminar. Journal on Excellence in College Teaching, 20(3), 5-28.

Guilford, J. P. (1973). Fundamental statistics in psychology and education. New York, NY: McGraw-Hill.

Huwari, I. F., \& Aziz, N. H. A. (2011). Writing apprehension in English among Jordanian postgraduate students at Universiti Utara Malaysia (UUM). Academic Research International, 1(2), 190-198.

Kader, A. A. (2016). Debilitating and facilitating test anxiety and student motivation and achievement in principles of microeconomics. International Review of Economics Education, 23, 40-46.

Krashen, S. D. (1981). Second language acquisition and second language learning. Oxford University Press.

Krejcie, R. V., \& Morgan, D. W. (1970). Determining sample size for research activities. Educational and psychological measurement, 30(3), 607-610.

Lavelle, E., Smith, J., \& O'Ryan, L. (2002). The writing approaches of secondary students. British Journal of Educational Psychology, 72(3), 399-418.

Maehr, M. L., \& Zusho, A. (2009). Achievement goal theory: The past, present, and future. In K. R. Wentzel \& A. Wigfield (Eds.), Handbook of motivation in school (pp. 77-104). New York: Taylor Francis.

Pajares, F \& Valiante. (2008). Self-efficacy beliefs and motivation in writing development. In C.A. Macarthur, S. Graham, \& J. Fitzgerald (Eds.), Handbook of writing research (pp. 158-170). New York: Guilford Press.

Pajares, F., \& Valiante, G. (1997). Influence of self-efficacy on elementary students' writing. The Journal of Educational Research, 90(6), 353-360.

Park, G. P., \& French, B. F. (2013). Gender differences in the foreign language classroom anxiety scale. System, 41(2), 462-471. 
Sabti, A. A. (2013). Investigating Writing Anxiety among Iraqi Post Graduate Students in $U K M$ (Unpublished master thesis). National University of Malaysia, Malaysia.

Sabti, A. A., Mansor, Y. T. M. B. T., Altikriti, M. Q., Abdalhussein, H. F., \& Dhari, S. S. (2016). Gender differences and foreign language reading anxiety of high school learners in an Iraqi EFL context. International Journal of Applied Linguistics and English Literature, 5(5), 208-214.

Schunk, D. H., \& DiBenedetto, M. K. (2016). Self-efficacy theory in education. In K. R. Wentzel \& D. B. Miele (Eds.), Handbook of motivation at school (pp. 34-54). New York, NY: Taylor \& Francis.

Schunk, D., \& Pajares, F. (2009). Self-efficacy theory. In K. R. Wentzel \& A. Wigfield (Eds.), Handbook of motivation in school (pp. 35-54). New York: Taylor Francis.

Senko, C. (2016). Achievement goal theory: A story of early promises, eventual discords, and future possibilities. In K. R. Wentzel, \& D. B. Miele (Eds.), Handbook of student motivation (pp. 75-95) (2nd ed.). New York: Routledge.

Senko, C., \& Miles, K. M. (2008). Pursuing their own learning agenda: How masteryoriented students jeopardize their class performance. Contemporary Educational Psychology, 33(4), 561-583.

Senko, C., Hulleman, C. S., \& Harackiewicz, J. M. (2011). Achievement goal theory at the crossroads: Old controversies, current challenges, and new directions. Educational Psychologist, 46(1), 26-47.

Tsao, J. J., Tseng, W. T., \& Wang, C. (2017). The effects of writing anxiety and motivation on EFL college students' self-evaluative judgments of corrective feedback. Psychological reports, 120(2), 219-241.

Valmori, L. (2016). Anxiety in interaction-driven L2 learning (Unpublished doctoral dissertation). Michigan State University, USA.

Yan, J. X., Pan, J., \& Wang, H. (2018). Second language writing anxiety and translation: performance in a Hong Kong tertiary translation class. In Research on Translator and Interpreter Training (pp. 169-190). Springer, Singapore.

Zailaini, M. A., Mohamed, M. F., Ismail, W. M., Ali, S. K. S., \& Muzammil, A. G. (2015). Writing Skill in Arabic Language Essay in Malaysian Secondary School. International Journal of Social Science \& Human Behavior Study, 2(2), 135-139.

Zhao, N. (2007). A study of high school students' English learning anxiety. The Asian EFL Journal, 9(3), 22-34. 


\section{Appendix (A) \\ Second Language Writing Anxiety Inventory (SLWAI) \\ Likert Scale}

\begin{tabular}{|c|c|c|c|c|c|}
\hline Value & $\mathbf{1}$ & $\mathbf{2}$ & $\mathbf{3}$ & $\mathbf{4}$ & $\mathbf{5}$ \\
\hline Answer & $\begin{array}{c}\text { Strongly } \\
\text { Disagree }\end{array}$ & Disagree & Uncertain & Agree & $\begin{array}{c}\text { Strongly } \\
\text { Agree }\end{array}$ \\
\hline
\end{tabular}

Please tick $(\sqrt{ })$ the appropriate answer which best suits for you.

\begin{tabular}{|c|c|c|c|c|c|c|}
\hline \multicolumn{7}{|c|}{ Facilitating Writing Anxiety Factor } \\
\hline No & Statement & 1 & 2 & 3 & 4 & 5 \\
\hline 1 & 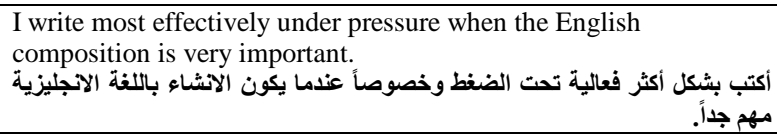 & & & & & \\
\hline 2 & 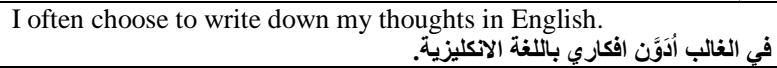 & & & & & \\
\hline 3 & $\begin{array}{l}\text { My mind often goes full of ideas when I start to write an English } \\
\text { composition. } \\
\text { غالبأ ذهني ما يكون مملوء بالافكار عندما ابدأ بكتابة الانثاء باللغة الاتجليزية. }\end{array}$ & & & & & \\
\hline 4 & $\begin{array}{l}\text { The more important the English composition, the better I seem to } \\
\text { do. } \\
\text { يبدو لي أن أعمل بثكل افضل عندما يكون الانثاء باللغة الانجليزية اكثر اهمية. }\end{array}$ & & & & & \\
\hline 5 & 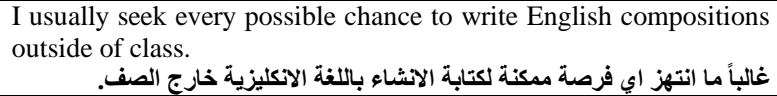 & & & & & \\
\hline 6 & 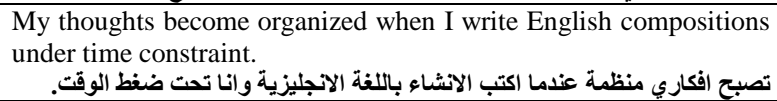 & & & & & \\
\hline 7 & 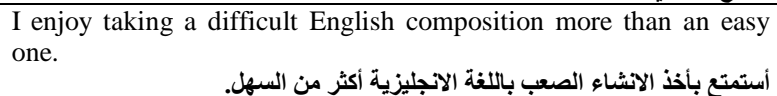 & & & & & \\
\hline 8 & 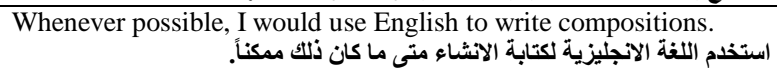 & & & & & \\
\hline 9 & 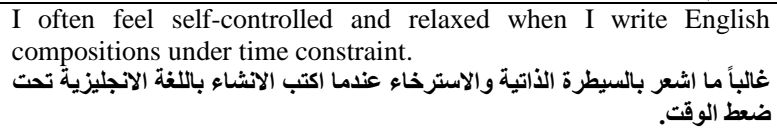 & & & & & \\
\hline 10 & 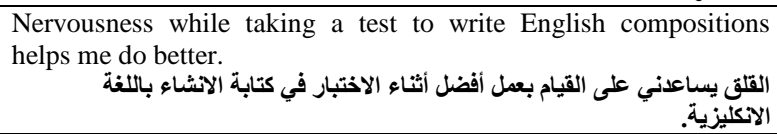 & & & & & \\
\hline \multicolumn{7}{|c|}{ Debilitating Writing Anxiety Factor } \\
\hline 11 & 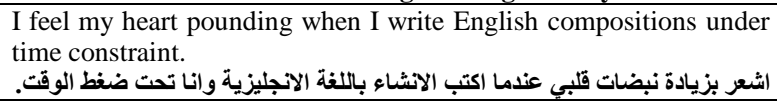 & & & & & \\
\hline 12 & 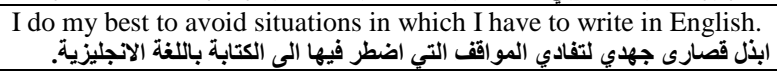 & & & & & \\
\hline 13 & 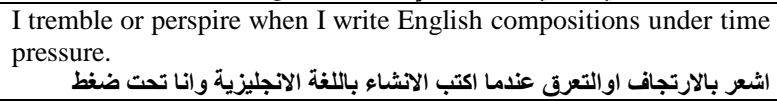 & & & & & \\
\hline
\end{tabular}

International Journal of Instruction, October $2019 \bullet$ Vol.12, No.4 


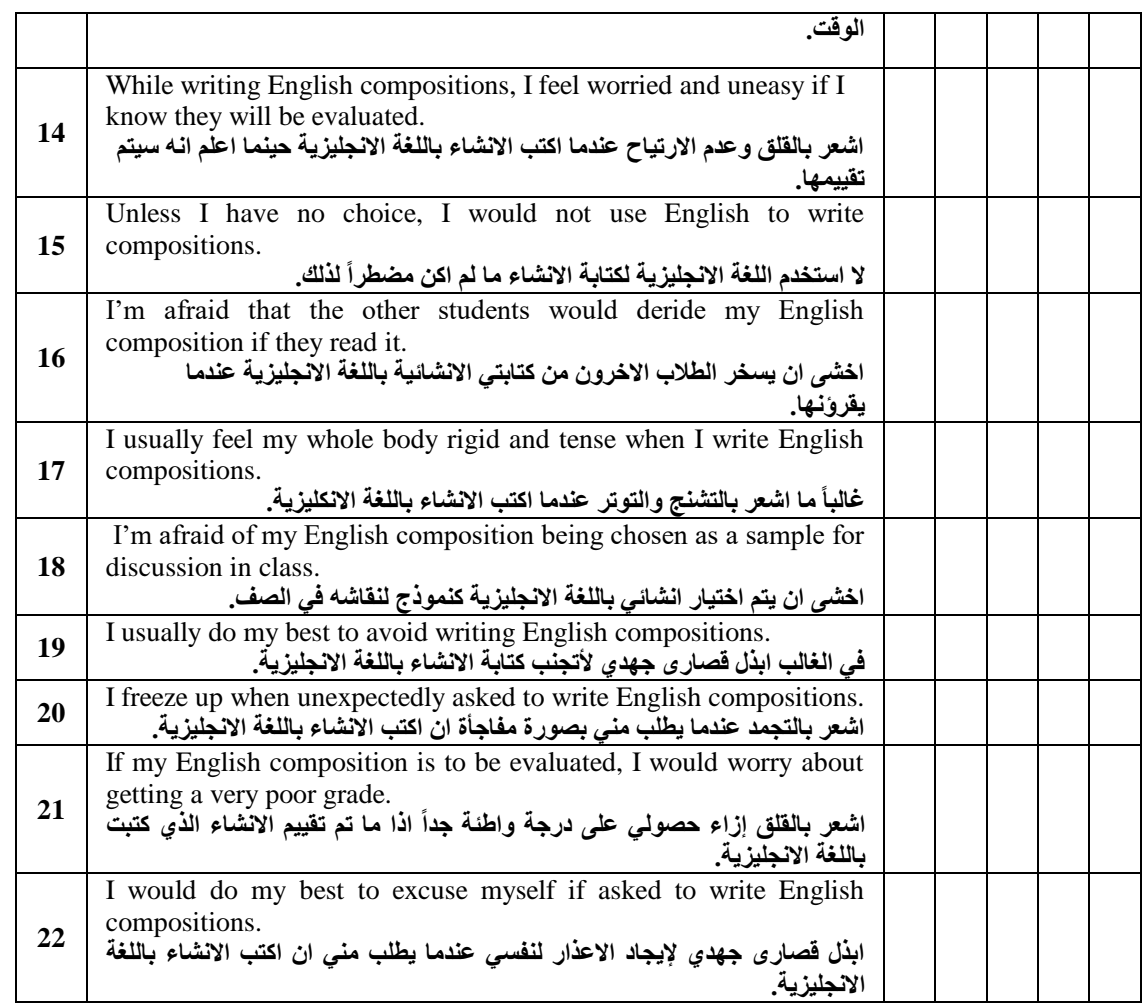

Appendix (B)
The Achievement Goal Questionnaire (AGQ)

Likert Scale

\begin{tabular}{|c|c|c|c|c|c|}
\hline Value & $\mathbf{1}$ & $\mathbf{2}$ & $\mathbf{3}$ & $\mathbf{4}$ & $\mathbf{5}$ \\
\hline Answer & $\begin{array}{c}\text { Strongly } \\
\text { Disagree }\end{array}$ & Disagree & Uncertain & Agree & $\begin{array}{c}\text { Strongly } \\
\text { Agree }\end{array}$ \\
\hline
\end{tabular}

Please tick $(\sqrt{ })$ the appropriate answer which best suits for you.

\begin{tabular}{|c|c|c|c|c|c|c|}
\hline$ت$ & 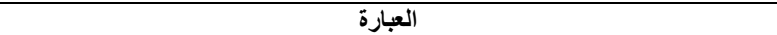 & 1 & 2 & 3 & 4 & 5 \\
\hline \multicolumn{7}{|c|}{ Mastery-Approach Goal Factor } \\
\hline 1 & 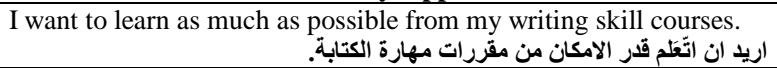 & & & & & \\
\hline 2 & 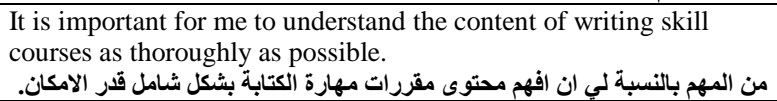 & & & & & \\
\hline 3 & 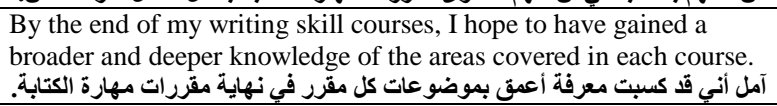 & & & & & \\
\hline
\end{tabular}

International Journal of Instruction, October $2019 \bullet$ Vol.12, No.4 


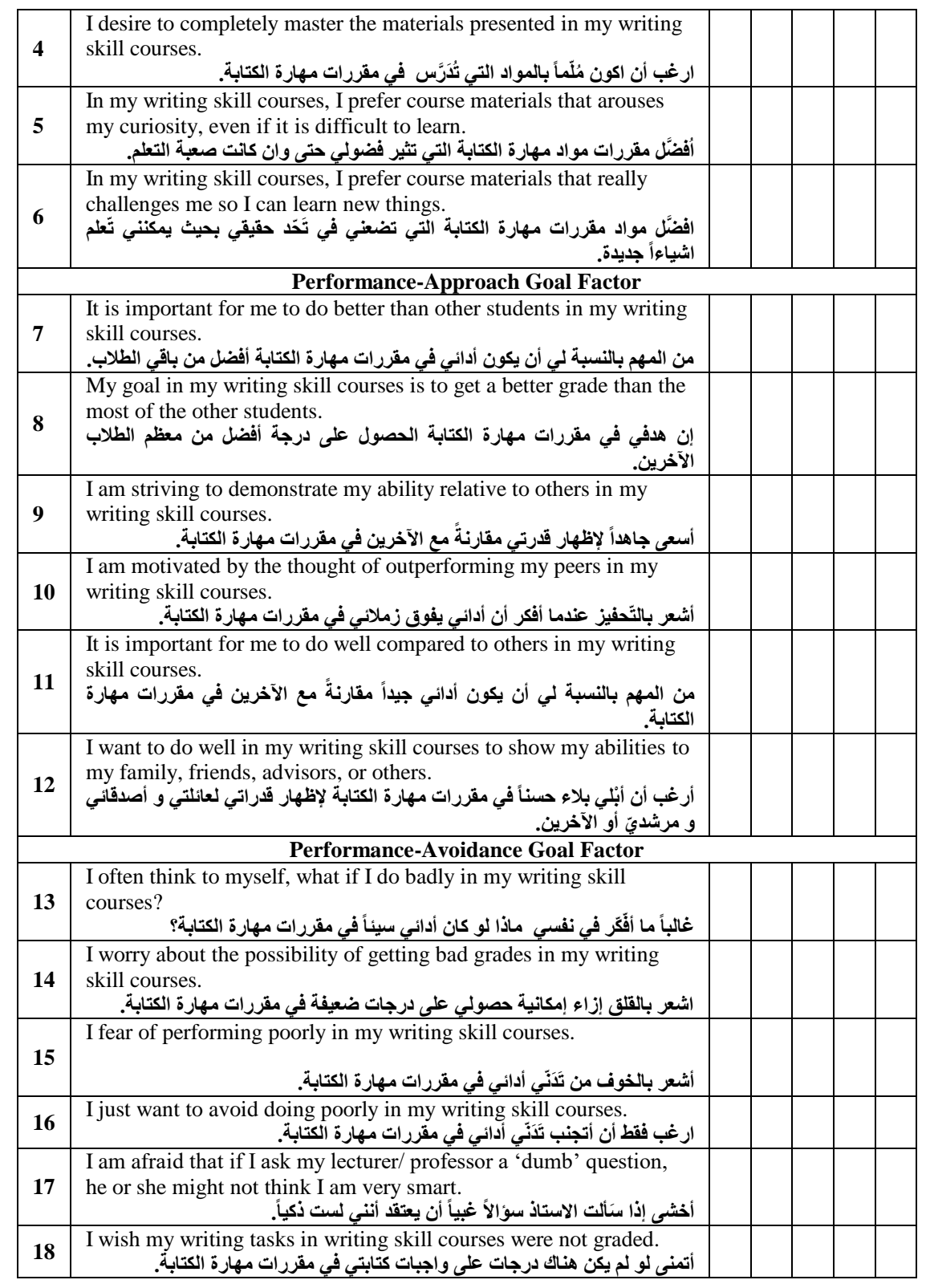

International Journal of Instruction, October $2019 \bullet$ Vol.12, No.4 